\title{
Erratum to: Differences in the heat stress associated with white sportswear and being semi-nude in exercising humans under conditions of radiant heat and wind at a wet bulb globe temperature of greater than $28^{\circ} \mathrm{C}$
}

\author{
Michio Tsuji • Masashi Kume • Hideyuki Tuneoka •
}

Tetsuya Yoshida

Published online: 31 January 2014

(C) ISB 2014

\section{Erratum to: Int J Biometeorol}

DOI 10.1007/s00484-013-0722-3

The authors would like to point out that the legend to Table 1 should read Comparison of heat storage (W) during rest and exercise. Different lower case letters a, b and c indicate significant differences $(P<0.05)$ between SP and WS, $50 \%$ and $20 \%$ and Rest and Exercise, respectively. WS White sportswear, $S P$ swimming pants

The online version of the original article can be found at $\mathrm{http}: / / \mathrm{dx}$.doi.org/ 10.1007/s00484-013-0722-3.

M. Tsuji $\cdot$ T. Yoshida $(\square)$

Graduate School of Science and Technology, Kyoto Institute of

Technology, Matsugasaki, Sakyo-ku, Kyoto 606-8585, Japan

e-mail: yoshida@kit.jp

\section{Kume}

Kyoto Bunkyo Junior College, Kyoto, Japan

H. Tuneoka

Kyoto Institute of Technology, Kyoto, Japan 